\title{
SINGULARIDADES NO PROCESSO DE TRABALHO ENTRE TÉCNICOS EM SAÚDE BUCAL E CIRURGIÕES-DENTISTAS
}

\author{
SINGULARITIES IN THE WORK PROCESS BETWEEN ORAL HEALTH TECHNICIANS AND \\ DENTAL SURGEONS
}

\section{SINGULARIDADES EN EL PROCESO DE TRABAJO ENTRE TÉCNICOS EN SALUD BUCAL Y CIRUJANOS DENTISTAS}

\author{
Eunice Assad Galvêas ${ }^{1}$ \\ Adauto Emmerich Oliveira ${ }^{2}$ \\ Carolina Dutra Degli Esposti ${ }^{3}$ \\ Edson Theodoro dos Santos Neto ${ }^{4}$
}

\begin{abstract}
Resumo Objetivou-se neste estudo compreender a relação entre técnicos em saúde bucal e cirurgiões-dentistas no trabalho e os fatores que podem favorecer ou dificultar essa relação. Para análise da percepção dos técnicos em saúde bucal sobre os possíveis encontros e desencontros da relação no trabalho com os cirurgiões-dentistas, realizou-se um grupo focal com oito desses trabalhadores do Sistema Único de Saúde de municípios da Grande Vitória, Espírito Santo. A análise de conteúdo temática revelou três categorias: Perfil e mercado de trabalho; Condições de trabalho e infraestrutura; e Formação profissional, processo de trabalho e relação interpessoal. A complexidade do trabalho foi evidenciada, dentro do campo de interesses, poder e resistências, envolvendo tanto os técnicos quanto os cirurgiões-dentistas numa matriz geradora de comportamentos. Também existe forte influência do sistema de formação desses trabalhadores, da infraestrutura e das condições de trabalho e do perfil profissional no processo de trabalho da equipe em saúde bucal. Vislumbrou-se na comunicação a mediação, construindo novos encontros. Considera-se que muitos são os entraves para a relação entre técnicos em saúde bucal e cirurgiões-dentistas no trabalho, e vislumbra-se na comunicação a mediação, construindo novos encontros e representando alternativas para profanação do instituído, com superação dos desafios nas relações de poder.
\end{abstract}

Palavras-chave pessoal técnico de saúde; odontologia em saúde pública; relações interprofissionais; recursos humanos em odontologia.
Abstract This study aimed to understand the relationship between oral health technicians and dental surgeons in work and the factors that may promote or hinder this relationship. To analyze the perception oral health technicians have regarding possible agreements and disagreements in their working relationship with dental surgeons, a focus group was held with eight of those workers from the National Health System working at the municipalities encompassed by the Vitória metro region, in Espírito Santo, Brazil. The thematic content analysis revealed three categories: Profile and labor market; Working and infrastructure conditions, and Vocational training, work processes, and interpersonal relationships. The complexity of the work was shown, within the field of interests, power and resistance, involving both the technicians and dental surgeons, in a behavior generator matrix. These workers' training system, the infrastructure, working conditions, and the professionals' profile also influence the oral health team's work process heavily. Communication was seen as a mediator in this, building new encounters. It is considered that there are many barriers to the relationship between oral health care technicians and dental surgeons at work, and mediation is seen to be possible through communication, building new meeting grounds, and representing alternatives to the desecration of what has been instituted, overcoming the challenges in the power relations.

Keywords Technical health personnel; dentistry in public health; inter-professional relations; human resources in dentistry. 


\section{Introdução}

Com as mudanças ocorridas na odontologia no decorrer da história, os cirurgiões-dentistas (CDs), no exercício de sua profissão, buscaram ampliar seus conhecimentos e tornar sua metodologia de trabalho mais eficiente. Houve a necessidade de incluir na prática odontológica o Pessoal Auxiliar em Odontologia (PAO), o que facilitou o processo de trabalho dos CDs, otimizando tempo e recursos e possibilitando a ampliação de cobertura populacional (Paranhos et al., 2008).

Apesar dos benefícios que o PAO trouxe à prática odontológica, a formação e os conflitos inerentes à consolidação dessa nova profissão na odontologia encontraram oposição dos CDs (Narvai, 1989). Esses não conseguiam vislumbrar os benefícios que o PAO poderia trazer, tais como expansão da oferta de serviços, otimização do tempo e do trabalho, aumento da produtividade e maior resolutividade das ações odontológicas. O trabalho que antes era exercido apenas pelos CDs, de forma individual e no espaço restrito dos consultórios, passou a ser compartilhado com outros profissionais de nível intermediário, sendo necessária uma adaptação de ambos (Frazão, 1998; Serra e Garcia, 2002; Zanetti, 2009).

O Serviço Especial de Saúde Pública (SESP) foi a instituição responsável, no estado do Espírito Santo, pelo pioneirismo da fluoretação da água de abastecimento em 1953, na cidade de Baixo Guandu, fazendo emergir a saúde bucal no âmbito das políticas públicas (Emmerich e Freire, 2003). Nesse contexto, as auxiliares de higiene dentária (AHD) compunham a equipe, desempenhando importante papel no programa de odontologia escolar, realizando a orientação de higiene bucal, aplicação de flúor e auxiliando os CDs na manipulação de materiais e instrumentais. Sua formação e competências eram reduzidas quando comparadas às de outros países, mas justificou-se no momento, com o objetivo de agilizar a inserção desses profissionais no mercado de trabalho e evitar o confronto desses profissionais com os CDs e suas associações (Chaves, 1977; Emmerich e Freire, 2003).

No Brasil, até a década de 1970, não havia instituições formadoras que pudessem subsidiar a formação do PAO. Somente a partir dessa década houve formalização dos primeiros profissionais intitulados técnicos de higiene dental (THD), apoiados na Lei de Diretrizes e Bases da Educação (Brasil, 1996), que enfatizava a educação para o trabalho. Além disso, o parecer n. 460/75 do Conselho Federal de Educação passou a regulamentar a formação do THD e do atendente de consultório dentário (ACD), disciplinando e regulando o funcionamento dos cursos de formação. Já na década de 1980, o Conselho Federal de Odontologia definiu as normas para habilitação ao exercício dos THDs, integrando-os aos Conselhos Regionais de Odontologia (CROs) (Frazão, 1998). 
Após esse período, o PAO passou a fazer parte da realidade dos processos de trabalho em saúde bucal junto aos CDs, além de construir e ocupar o seu próprio espaço social por meio do trabalho compartilhado em equipe. Houve a necessidade de rever o seu papel, tanto como membro de uma Equipe de Saúde Bucal (ESB) quanto como um indivíduo que traz um novo saber. Desde então, a preocupação com a utilização desses profissionais nas funções clínicas e educativas vem crescendo (Paranhos et al., 2008; Pezzato, 1999).

Nesse contexto, o PAO torna-se cada vez mais necessário ao exercício da odontologia e ao trabalho da equipe odontológica, ocupando novos espaços sociais, tanto nos consultórios privados quanto no campo da saúde pública. Com a inserção da odontologia na Estratégia Saúde da Família (ESF) em 2000, por meio da portaria n. 1.444, do Ministério da Saúde, buscou-se ampliar as ações de saúde, assegurando ações preventivas e de promoção à saúde bucal aos usuários do Sistema Único de Saúde (SUS). Nesse cenário, o PAO passou a ter novas oportunidades de atuação, pois os municípios candidatos à habilitação para obtenção de recursos financeiros deveriam formar equipes compostas de CD e ACD (modalidade I) ou CD, ACD e THD (modalidade II). Assim, os THDs tornaram-se fundamentais e obrigatórios para a constituição da ESB na modalidade II, evidenciando a sua importância como facilitador do trabalho em odontologia e na constituição de uma equipe (Brasil, 2000).

Contudo, mesmo com a necessidade do registro no CRO, para o exercício da profissão, somente em 2008 encerrou-se a longa trajetória de esforços para o reconhecimento legal desses profissionais. Por meio da lei n. 11.889, os THDs passaram a ser denominados técnicos em saúde bucal (TSB) e os ACDs auxiliares de saúde bucal (ASB) (Conselho Regional de Odontologia de Minas Gerais, 2008), com poucas modificações em suas atribuições e com muita polêmica na interpretação de seu enunciado (Frazão e Narvai, 2011; Zanetti, Oliveira, Mendonça, 2012). O impacto social e a importância desses atores, para prevenção de doenças e para promoção da saúde, na ESB junto à população, foram fundamentais para a melhoria da qualidade da atenção primária e estruturação da equipe de saúde bucal, o que permitiu melhor divisão de tarefas, agilidade e otimização do trabalho do $\mathrm{CD}$, que, atuando em equipe, terá seu trabalho potencializado com o entendimento da referida lei, atendendo aos anseios da saúde coletiva (Conselho Regional de Odontologia de Minas Gerais, s.d.).

A partir da inserção legal dos TSBs no SUS, torna-se fundamental pensar como vêm ocorrendo a integração e a articulação da relação no trabalho desses profissionais com os CDs na ESB. Uma equipe integrada e bem-articulada é fundamental para a melhoria da qualidade das ações de saúde, visto que a relação harmoniosa desta equipe traz benefícios internos à instituição e à comunidade. Isso resulta na ampliação do acesso, na assistência de melhor qualidade e numa odontologia mais social (Brasil, 2004). 
Ao notabilizar a relação de trabalho entre TSB e CD, ressalta-se um campo social ora de encontros, ora de desencontros. A forma como é vivenciada dependerá de como são construídas as relações no trabalho e interpessoais, além da cooperação entre eles. A cooperação interprofissional é uma forma eficiente, eficaz e satisfatória para ofertar os serviços de saúde. O processo de colaboração é construído por uma estrutura voluntária e implica necessariamente negociação, na qual as partes deixam de ter uma abordagem competitiva e passam a adotar uma abordagem participativa e em equipe (D'Amour, 2005).

O mundo social do trabalho é visto como um espaço com diversas dimensões, baseado nos princípios de diferenciações ou de distribuições que se constituem por meio de uma série de propriedades ativas, que conferem força ou poder. Desta maneira, todos os indivíduos ou grupos se definiriam pela posição que ocupariam dentro desse espaço social, campo de forças, de relações de poder objetivas, que se imporiam a elas mesmas e a todos que entrassem no campo. Assim, os conflitos existentes em um trabalho em equipe, como a ESB, podem ocorrer em função das diferentes subjetividades que transitam no campo das relações construídas pelos atores envolvidos (Bourdieu, 1996). Neste espaço de tensões, conflitos e jogos de poder, poderá ser construído um ambiente de negociação, de respeito mútuo para cada um dos comportamentos dos profissionais que constituem a equipe na produção do cuidado em saúde.

Nessa perspectiva, os encontros nas relações de trabalho entre TSB e CD podem gerar ações mais efetivas aos usuários do território de saúde e trazer mudanças no serviço que desempenham tanto nos processos de trabalho individuais quanto coletivos. Diante deste fato, o cuidado em saúde bucal não é somente de responsabilidade de um profissional, ou relativo a um campo de competências, mas sim de responsabilidade de vários profissionais.

Todos os saberes e fazeres dos envolvidos nesse processo de cuidado tornam-se recursos em potencial para defender a saúde. Os profissionais responsáveis pela produção do cuidado odontológico, articulados pela dimensão cuidadora e desalienante, por meio dos seus encontros, podem gerar mais atos de saúde ao invés de uma produção isolada, exclusiva de apenas um campo de competência (Cavalcante Filho, 2009).

Dessa forma, este estudo objetivou compreender as singularidades existentes na relação de trabalho entre os TSBs e cirurgiões-dentistas, sujeitos desta pesquisa, e os fatores que podem favorecer ou dificultar essa relação.

\section{Metodologia}

Este estudo 5 com abordagem qualitativa procurou retratar a perspectiva dos TSBs inseridos no SUS de quatro municípios da Região Metropolitana da 
Grande Vitória (RMGV), no Espírito Santo. A região é composta por sete municípios. Destes, quatro (Cariacica, Serra, Vila Velha e Vitória) apresentavam profissionais TSBs em atuação profissional no serviço público na época do estudo.

Observando-se que os municípios divergem quanto ao estágio de implantação das ESBs e, consequentemente, à quantidade desses profissionais de nível técnico, o critério de seleção para compor o grupo focal considerou a proporção de trabalhadores em exercício profissional de cada município. Para identificação dos possíveis sujeitos da pesquisa, que integrariam o grupo focal, procedeu-se ao contato com as secretarias municipais de saúde. Foram convidados 12 profissionais, mas quatro não compareceram.

Nos municípios com até três profissionais, todos os TSBs foram convidados; e nos municípios com mais de três profissionais, utilizou-se como critério o maior tempo de atuação na função de técnico, tendo sido convidados quatro de cada município.

A técnica do grupo focal tem como principal característica trabalhar com a fala em debate e ser indicada para situações que, ainda inconclusas, precisam ser amplamente discutidas pelos profissionais da área com o propósito de obter informações de caráter qualitativo em profundidade (Cruz Neto, 2001; Richardson, 1999).

A coleta do material ocorreu no mês de agosto de 2010, em horário de final de expediente. A integração inicial entre os participantes aconteceu por meio de uma recepção com um lanche. Em seguida, os participantes sentaram-se em torno de uma mesa, numa sala de reunião reservada no Centro de Ciências da Saúde da Universidade Federal do Espírito Santo (CCS/UFES), onde todos os oito TSBs que compareceram assinaram o termo de consentimento livre e esclarecido.

No Quadro 1, apresentam-se as características dos sujeitos da pesquisa, destacando-se que todos eram do sexo feminino, apenas duas possuíam uma carga horária de trabalho de trinta horas semanais e as outras exerciam quarenta horas semanais. Em relação à formação desses profissionais, seis formaram-se no Espírito Santo, uma em São Paulo e uma no Rio Janeiro. Os TSBs estão representados por números de um a oito e os municípios por letras de A a D. 
Quadro 1

\begin{tabular}{|c|c|c|c|c|c|c|c|}
\hline TSB & Idade & Município & Vínculo & Lotação & $\begin{array}{l}\text { Tempo } \\
\text { trabalho }\end{array}$ & $\begin{array}{l}\text { Tempo } \\
\text { formado }\end{array}$ & $\begin{array}{l}\text { Estado de } \\
\text { formação }\end{array}$ \\
\hline 1 & 30 & A & Temporário & Policlínica & 3 meses & 5 anos & ES \\
\hline 2 & 27 & B & Efetivo & Unidade Básica de Saúde & 3 anos & 5 anos & ES \\
\hline 3 & 53 & B & Consolidação das Leis Trabalhistas & Unidade de Saúde da Família & 5 anos & 5 anos & ES \\
\hline 4 & 44 & B & Consolidação das Leis Trabalhistas & Unidade de Saúde da Família & 7 anos & 11 anos & SP \\
\hline 5 & 45 & C & Efetivo & Unidade Básica de Saúde & 8 anos & 10anos & ES \\
\hline 6 & 42 & C & Efetivo & Unidade de Saúde da Família & $2 a 5 m$ & 10anos & ES \\
\hline 7 & 38 & B & Consolidação das Leis Trabalhistas & Unidade de Saúde da Família & 5 anos & 8 anos & ES \\
\hline 8 & 53 & D & Efetivo & Departamento Escolar & 6 anos & 25 anos & RJ \\
\hline
\end{tabular}

Fonte: Os autores.

TSBs: Técnicos em saúde bucal

A equipe de pesquisadores que participou do grupo focal era composta por um mediador, dois digitadores relatores, dois assistentes de gravação de áudio e três observadores externos que anotavam as impressões percebidas. Ao término da aplicação da técnica, realizou-se uma reunião com os pesquisadores para discussão e comentários sobre os pontos mais relevantes.

O material foi examinado segundo a análise de conteúdo temática sugerida por Bardin (2009), seguindo sua sequência técnica dividida em três momentos que não são estanques, mas que se entrelaçam. No primeiro, houve a elaboração do material a ser analisado, por meio da audição e transcrição das falas, na íntegra. No segundo, fez-se a exploração do material, por meio da leitura flutuante do texto, destacando-se frases com comentários, na lateral esquerda, sobre o tema a que elas se referiam. No terceiro momento, elaborou-se uma grade de categorização das falas mais significativas em relação aos temas abordados e tratados na literatura, para a apreensão dos significados (Bardin, 2009; Minayo, 2008).

No material empírico, buscaram-se sinais e pistas que pudessem nortear a compreensão sobre como é construída a relação no trabalho daqueles profissionais com os CDs na ESB, bem como o que pode favorecer ou dificultar essa relação. Essas pistas e sinais deram origem a três categorias de análise: Perfil e mercado de trabalho; Condições de trabalho e infraestrutura; e Formação profissional, processo de trabalho e relação interpessoal.

A pesquisa obteve aprovação do Comitê de Ética em Pesquisa do CCS/UFES, sob o n. 044/10. 


\section{Resultados e discussão}

As ações que são desenvolvidas pela ESB exigem que TSBs e CDs tenham conhecimento técnico, habilidades, iniciativa, domínio da clínica e das tecnologias, bem como capacidade de trabalho em conjunto com clareza dos papéis desempenhados pelos atores. Deve-se compreender que o trabalho em equipe tem que ser destituído do verticalismo no exercício do poder, ser compartilhado e harmonizado, isto é, circular entre os trabalhadores nos diversos momentos devido às suas singularidades. Além disso, o processo de trabalho desenvolvido por TSBs e CDs torna-se altamente relacional, ora por meio de acordos harmoniosos, ora como resultado de tensões e conflitos, mediados pela linguagem no 'corpo-a-corpo' que se estabelecem (Merhy, 2002; Latour, 2008). Essas relações são mediadas por condições sócio-históricas situadas no cotidiano do processo de trabalho.

\section{Perfil e mercado de trabalho}

Os TSBs e os CDs, ao exercerem seus processos de trabalho, trazem consigo toda a subjetividade de seus mundos que são expressos em suas relações interpessoais. Apoiando-se em Foucault (2007), é possível afirmar que a subjetividade é o reflexo de nossa relação com as coisas, por meio e através da história. Essa relação se expressa pelo corpo, compreendido não somente como corpo orgânico, mas como corpo construído pelas relações com as coisas que se encontram ao longo da caminhada e da existência de cada indivíduo. Assim, trata-se da descrição de uma história cujos conteúdos se aproximam de uma estética da própria existência de cada um.

Na subjetividade, não há um sujeito teórico, e sim um sujeito sintetizado pelas experiências, nas quais a subjetividade é a própria trama da vida e das relações que se compõem (Latour, 2008). E essa composição de diferentes universos (Bourdieu, 1996) que habitam cada existência e se configuram sob a forma de afeto sempre será versátil aos novos arranjos, sejam quais forem, familiares, institucionais, entre atores de um grupo, ou outros (Foucault, 2007).

Segundo Dejours (1993), o trabalhador não chega ao local de trabalho como uma máquina nova, ele tem uma história, aspirações, desejos, motivações, necessidades psicológicas e outros. Uma vez que cada trabalhador tenha características únicas e pessoais e que essas determinem quem de fato são esses trabalhadores, torna-se um desafio uma relação com outro profissional, que também traz sua história, suas características, seus desejos, aspirações, motivações, bem como receios, medos e dificuldades de se relacionar. 
Aí, assim aos poucos, eu fui me acostumando, mas no início foi barra, porque às vezes eu batia de frente; meu entrosamento não foi muito legal no início.

Segundo Malory (1987), os conflitos podem ser gerados pelos caminhos diferentes para se alcançar os objetivos, a personalidade dos indivíduos, as diferenças de valores, a superposição ou a falta de clareza de papéis, a falta de informação, ou mesmo o abuso de poder por parte daqueles que têm maior prestígio social. Portanto, esse é um fato da vida esperado em qualquer relação interpessoal, e no local de trabalho pode ser um fenômeno natural que, se administrado construtivamente, ao invés de gerar conflitos e desagregações, pode até fortalecer as relações e torná-las mais agradáveis. Situações semelhantes para Bourdieu (1996) configuram-se como a influência do habitus e do campo dos atores envolvidos no ambiente de trabalho.

Fleuri (2002) deixa como reflexão que as pessoas trazem heranças significativas em suas vidas, sejam elas culturais, sociais, familiares, de grupo ou individuais, juntamente com experiências e práticas, valores, características e formação específica para exercerem suas funções ou viver sua própria existência. E isso determina a comunicação que essas pessoas irão travar no eu cotidiano, em todos os níveis e dimensões. São relações que se darão entre sujeitos que decidem novos contextos e processos de aproximação, de conhecimento recíproco e de interação.

Na perspectiva de Freire (1999), o ser humano, por não estar enclausurado ao determinismo, torna-se inconcluso e, enquanto inconcluso, a todo o momento, pode se humanizar e construir novas histórias e escolher novos caminhos a serem trilhados, desenvolvendo junto a outras pessoas ou profissionais novas perspectivas de encontros, de trabalhos, de vivência em equipe. No debate se contrastaram tanto a sensação de clausura quanto a de liberdade e reconhecimento social:

Eu tinha abertura na cadeira para fazer alguns procedimentos. Hoje em dia não, nenhuma abertura, não tem cadeira. Consultório vazio, parado, tem, mas para a THD trabalhar, não. Igual eu falei, a minha agenda diária é cheia, direto com palestra e raios $\mathrm{X}$.

É por isso que eu falo que o meu trabalho se faz melhor dando palestras, indo para a escola, porque assim eles [usuários] estão conhecendo a TSB, estão conhecendo o trabalho. Se eu ficar dentro do consultório, ninguém vai conhecer.

As condições epidemiológicas de saúde bucal e a racionalização da assistência odontológica no Brasil preconizam que o TSB integre a ESB, na qual o sujeito do trabalho é coletivo e o TSB pode realizar plenamente o sentido social do seu trabalho. Há mais de uma década essa discussão vem sendo realizada 
por autores como Narvai et al. (1989) e Carvalho (1999), que afirmam que essa participação dos TSBs no trabalho em saúde bucal possibilita liberação dos profissionais de nível superior das funções mais simples, porém não menos importantes, aumentando a cobertura dos serviços odontológicos a um custo menor. Isso sugere novas perspectivas de inserção no mercado de trabalho, tanto no setor público quanto privado, também evidenciadas nos seguintes depoimentos:

Eu acho que o mercado, ele... lógico que se eu tiver uma vasta experiência, vai ser muito bom para mim, tanto para o meu trabalho como para estar passando para os colegas. Mas, para o mercado, o que vale é o certificado.

Falta o CRO soltar mais um pouco, liberar mais o mercado, o técnico, o conhecimento, expandir para você mostrar o seu lado profissional aqui no estado.

O número de TSBs permanece praticamente inalterado, mesmo após a expansão da Saúde da Família (Zanetti, Oliveira e Mendonça, 2012). No entanto, com base nas constatações desse estudo, vislumbra-se a possibilidade dos TSBs traçarem novas histórias, comuns e singulares com os CDs, em uma perspectiva coletiva em equipe, com novas vivências, novas intervenções e ações estratégicas para a atenção à saúde bucal no SUS. Deve-se considerar a influência do campo e habitus nessa interação estabelecida por eles no cotidiano dos serviços.

\section{Condições de trabalho e infraestrutura}

Nas instituições e serviços de saúde, a atuação de CDs e de TSBs depende de recursos adequados que devem estar disponíveis, tais como espaço físico, infraestrutura, materiais, insumos e recursos humanos suficientes e capacitados, garantindo os meios para que esses profissionais desempenhem suas atribuições e competências de modo a contribuir para a melhoria dessas instituições e serviços (Esposti et al., 2012; Frazão e Narvai, 2009; Pucca, 2006). O Ministério da Saúde já previu tal imperativo, ao estabelecer e disponibilizar recursos financeiros para a aquisição de dois equipamentos odontológicos (cadeira, foco e unidade auxiliar) para o trabalho de uma ESB modalidade II na ESF, composta por CD, TSB e ASB (Pucca, 2006). Entretanto, a ausência de infraestrutura para atuação dos TSBs esteve muito presente no debate do grupo focal, como se observa nas falas a seguir:

Não tem espaço para colocar mais uma cadeira, alegaram que não podia colocar equipe II. 
(...) Porque eu sou a THD, eu não tenho uma sala, eu não tenho uma mesa, eu não tenho um computador. Então eu sou a 'pedinte'.

Procurando compreender um pouco melhor esse campo social relacionado às condições de trabalho e à atuação de CDs e de TSBs como de conflitos e de poder no sentido bourdieusiano, pressupõe-se que apresenta potencialidades e um futuro provável de realizações, no qual o habitus adaptado e gerado neste campo pode ser capaz de antecipar transformações (Bourdieu, 2010). Portanto, pode-se depreender que o habitus aqui deslindado é como uma matriz geradora de comportamentos e visões de mundo relacionadas ao lugar social dos sujeitos (Bourdieu, 1996), onde a percepção que se tem é a de que é destinado ao pessoal do nível médio da saúde sujeições a condições de desvalorização e subutilização de suas funções e atribuições nos serviços de saúde, ora por desorganização destes, ora pela falta de incentivo e infra-estrutura, além de condições de trabalho inadequadas. Segundo os relatos dos profissionais, o vínculo empregatício é precário, há déficit de recursos humanos, com sobrecarga laboral.

(...) está com falta de ASB, porque até os contratos anteriores, o salário é muito baixo, baixíssimo, então não tinha ASB nenhuma querendo ir para lá [município], e, além disso, não tinha férias, $13^{\circ}$ salário e nem insalubridade.

Cada dia a gente tem uma agenda, fora, assim, se falta um funcionário na recepção, vamos lá para a frente dar uma mão para a recepção atender. É o dentista que chegou e não tem atendente, vamos arrumar o consultório (...).

A ACD que tinha, ela ia para o expurgo, então eu acabava sendo ACD e THD na época.

Condições precárias de trabalho e de infraestrutura dos serviços trazem vários problemas aos profissionais. A colaboração e a boa relação no trabalho requerem uma configuração organizacional favorável. Esses determinantes organizacionais incluem apoio administrativo, recursos para a equipe, comunicação aberta e mecanismos de coordenação democrática, cooperação interprofissional, valorização da participação igualitária de todos nos processos de trabalho e liberdade de expressão para que possam falar das suas dificuldades e necessidades (San Martin-Rodriguez et al., 2005).

\section{Formação profissional, processo de trabalho e relação interpessoal}

Cada profissional de saúde aprende seu papel pelo processo de educação de sua profissão, no qual se torna parte integrante do 'mapa cognitivo' 
do indivíduo. Se esse processo de educação foi articulado em um modelo individualista, hegemonista e flexneriano, dificilmente esses profissionais vão conseguir desempenhar seus papéis em um modelo de atenção integral, com trabalho em equipe e ações partilhadas. Assim, no desempenho de papéis, as profissões de maior ascendência social passam a ter privilégios nos espaços onde se inserem, o que pode gerar várias tensões e conflitos com os demais profissionais que não obtêm tais regalias e dificultar ainda mais a interação e integração desses (Hall e Weaver, 2001). Já durante a formação dos TSBs, os CDs professores demonstraram desvalorização em relação aos técnicos, como percebido no grupo focal:

Tivemos professores que na nossa cara disseram assim: THD, para mim, é um ACD melhorado (...) porque se estava falando assim na aula, imagina como ele ia respeitar $[\mathrm{O}$ TSB].

As instituições formadoras, além de dar subsídios técnicos e intelectuais para o exercício da clínica odontológica e das funções e atribuições dos TSBs, devem também promover meios para que esses profissionais se tornem protagonistas nesta cogestão, principalmente no âmbito do trabalho em equipe, como forma de integração de todos profissionais envolvidos com essas instituições, bem como entre si (Pereira, 2008). Na formação do nível médio, a desvinculação da educação geral da educação profissional trouxe prejuízos à formação desses profissionais. Assim, ao invés de terem suas perspectivas de trabalho ampliadas por um processo de educação integral do ser, que deveria prepará-los para um 'contínuo aprender a aprender', essa formação, desvinculada entre ensino médio e formação técnica, acabou se restringindo a um elenco de competências e habilidades de bases tecnológicas determinadas pelo mercado de trabalho (Ferretti, 1997; Morin, 2003), conforme debatido:

(...) porque [a instituição formadora] não dispunha de um aparelho [radiográfico], e a doutora, que era a nossa professora, ofereceu o consultório dela, particular.

Eu tive que apresentar monografia no meu curso; eu tive que fazer montagem em charneira; eu tive que fazer laboratório com acidente para buco-maxilo.

Isso confere aos TSBs uma concepção de formação profissional que não possibilita o desenvolvimento de uma visão crítica da motivação sócio-histórica do homem para a produção do conhecimento, mas sim o fazer mecânico, ao qual se tornam facilmente subordinados (Ferretti, 1997; Morin, 2003). Certamente, porque esses profissionais estão submetidos ao mesmo modelo de formação que privilegia o individualismo e a especialização. No entanto, foi possível perceber que a formação profissional do TSB pode ser mais 
interdisciplinar, em consonância com os princípios do SUS, mesclando os conhecimentos técnicos aos de Saúde Coletiva.

A minha turma, a gente estudava junto com os acadêmicos, (...) para entrar, para começar a fazer o curso, tinha que ter um livro que custava um absurdo, Mario Chaves, Odontologia Social, eu estudei nesse livro; depois eu tive outro livro de procedimentos de consultório básico.

O TSB deve ser preparado para vivenciar a relação em equipe, e para isso também deve estar bem qualificado e recebendo educação permanente, reforçando seus conteúdos e conhecimentos técnicos e clínicos, bem como aperfeiçoando as relações com o CD e com os demais profissionais do serviço (Emmerich e Castiel, 2009). Contudo, podem estar qualificados, semiqualificados, ou até mesmo sem qualquer preparo formal para o trabalho no consultório odontológico, ou seja, exercendo as atividades após serem treinados e qualificados pelos CDs, de acordo com suas necessidades e metodologias de trabalho (Frazão, 1998).

Depois que eu me formei, eu enxergo assim, tanto como existe o técnico ruim, esclarecendo melhor, existe o dentista ruim, o engenheiro ruim. Então, vai da sorte profissional. (...) Se o profissional CD tem um técnico ruim, que aprendeu pouco, que não sabe, ele vai aprender um pouquinho.

Apesar dos incentivos e portarias conjuntas dos ministérios da Saúde e da Educação, como o Programa Nacional de Reorientação da Formação Profissional em Saúde (Pró-Saúde) (Brasil, 2005) e o Programa de Educação pelo Trabalho para a Saúde (Pet-Saúde) (Brasil, 2008), as instituições formadoras, nos diferentes níveis de formação, não têm refletido mudanças significativas na conduta do profissional.

Torna-se necessário pensar em uma proposta curricular a favor da educação emancipatória, com conteúdos e práticas que possam evidenciar o trabalho em saúde numa perspectiva integral e em equipe, com prática privilegiada para uma inter-relação dos profissionais que irão constituir tais equipes, com base no entendimento das relações que se estabelecem entre eles. Deve se basear na solidariedade com o outro, no respeito e na ética, não cabendo mais esse modelo retrógrado, no qual alguns grupos, por deterem mais privilégios, passam a determinar todas as regras e atitudes da equipe (Pereira, 2008). A profissão técnica está mais sujeita tanto à ação da autoridade administrativa quanto à dos profissionais de nível superior. Deve ser evidenciado que é sobre os profissionais de nível técnico que mais recaem as pressões e controles que emanam da hierarquia, fundados na legitimidade do saber dos outros profissionais de nível superior (Farias e Vaitsman, 2002). 
Algumas dificuldades no trabalho em equipe e nas relações entre os profissionais que a constituem, refletindo nesse caso específico sobre os TSBs, podem advir de situações que foram construídas ao longo da história de cada profissão, tais como conflitos, poder, autoritarismo, hierarquia, inflexibilidade, desconhecimento do trabalho e da importância do outro, bem como das suas atribuições e funções legais (Pedrosa e Teles, 2001). Essas são situações corriqueiras nesse contexto de trabalho, conforme debatido pelos TSBs:

O TSB pode fazer o que o ACD faz. Mas não pode fazer o que o dentista faz. Então, existe uma hierarquia aí que fixa, que pode descer, mas não pode subir (...). Existe isso preestabelecido.

Então, você tem que ser respeitada pelo serviço que faz, que é a sua atribuição; então o que é seu, você faça direito. Não queira fazer o do outro, que aí você já está atropelando o do outro.

Na presença do ASB, nenhum TSB é obrigado a realizar rotineiramente as competências de um ASB (Zanetti, Oliveira e Mendonça, 2012). Apesar disso, os conflitos internos em equipes de saúde bucal podem ter como fatores propiciadores o poder desigual entre CD e TSB, como também a complementaridade, a apreensão e o compartilhamento de um novo objeto de trabalho que passam a conflitar com a autonomia técnica que os profissionais buscam alcançar. $\mathrm{O}$ conflito ocorre porque os profissionais buscam uma forma de trabalho tal como a tradição na prática do tipo liberal, atendendo isoladamente e tomando as decisões técnicas por si, baseadas em sua autoridade individual, o que é muitas vezes realizado de maneira quase subjetiva (Schraiber, 1999). A percepção dos TSBs em relação aos modos como os CDs da RMGV-ES interagem nas ESBs foi unânime:

O dentista do ES [Espírito Santo] não abraça o técnico. Ele não dá oportunidade pro técnico.

Contudo, a partir da inserção do TSB no mercado de trabalho, experiências positivas puderam ser vivenciadas, incluindo a reciprocidade entre técnicos e CDs, assim expressadas:

Eu tenho colegas na minha turma que sentaram [no equipamento odontológico] desde o início e hoje são excelentes no que fazem. Sabe? Assim, gostam.

(...) e quando os profissionais me abraçaram, eu cresci mais ainda.

Segundo Teixeira (2005), apesar de todas as dificuldades em lidar com outro profissional e dos conflitos e das relações conturbadas que se estabelecem 
entre eles, não há como desenvolver sozinho o cuidado em saúde, pois nenhum profissional detém em sua 'caixa de ferramentas' todos os saberes e fazeres necessários para dar conta das necessidades e cuidados integrais aos usuários. Todos os referenciais devem ser tidos como legítimos, mas não suficientes, tornando-se necessário que o trabalho na saúde seja realizado por um coletivo organizado para a produção de atos de saúde centrados no cuidado. É aceitando e valorizando o potencial das diferentes configurações de saberes e fazeres que os encontros são construídos. A noção de trabalho em equipe vislumbra tanto uma visão potencializadora das transformações dos modos de fazer saúde bucal quanto dos anseios idealizados para a prática da saúde coletiva no SUS.

A equipe de saúde bucal não é o dentista e o auxiliar. Equipe é o dentista, o técnico e o auxiliar, porque eu acho que sem o técnico não é equipe, é apenas o dentista e a auxiliar.

Era o nosso sonho trabalhar com as equipes mais inseridas, de participar das reuniões de equipe, fazer visitas no dia certinho, trabalhar mais na equipe com os agentes comunitários de saúde.

Os profissionais responsáveis por essa produção de cuidado, articulados pela dimensão cuidadora, desalienando seu trabalho, podem, por meio desse encontro, gerar mais atos de saúde ao invés de uma produção isolada (Cavalcante Filho, 2009) exclusiva conforme as competências, mas influenciada pelo campo dos atores no ambiente laboral (Bourdieu, 1996). A partir das discussões, foi possível compreender que, quando o processo de trabalho da ESB ocorre mediado por encontros, a excelência do atendimento aos usuários pode ser alcançada na atenção à saúde bucal:

(...) porque eu e minha dentista, a gente trabalha em conjunto. Precisou de raspagem? Eu vou cuidar daquela área, para depois ela fazer o procedimento.

Tem três equipes, tem três dentistas, três TSBs, três ASBs (...). Tem minha equipe, tem a dentista, tem a minha auxiliar, tem a minha escola, minha visita.

Outros relatos se sobressaíram, sugerindo que em alguns momentos os TSBs são subutilizados nos municípios, enquanto em outros há engessamento de função, evidenciando a diversidade quanto às múltiplas e precárias realidades dos processos de trabalho, entre elas a falta de gestão.

A secretaria tem que preconizar que o $\mathrm{ACD}$ deve tirar férias junto com o $\mathrm{CD}$, porque senão o THD vai ficar sem atender na escola. Eles pedem para a gente tirar 
férias junto com as férias escolares, julho ou janeiro, de modo a não atrapalhar o nosso trabalho na escola.

Além dessas condições, a falta de articulação entre os profissionais, a inflexibilidade, a verticalização das atividades, a falta de democracia nas decisões e nas ações da equipe podem favorecer uma desarticulação da equipe e um distanciamento entre os profissionais, gerando obstáculos não somente na relação entre eles como também em seus processos de trabalho. É necessário que a equipe se organize e se una para não permitir que esses obstáculos afetem seus processos de trabalho (Oliveira, 2006), assim como supere a competição existente entre CDs e TSBs (Zanetti, Oliveira e Mendonça, 2012). Entretanto, deve-se ressaltar que esses fatores sempre estão permeados pela subjetividade dos sujeitos, diretamente influenciados por suas trajetórias de formação e qualificação profissional.

Na relação entre TSBs e CDs, o 'abraçar' sugere que uma relação afetiva estabelecida que impregna na prática profissional a produção do cuidado gere uma robustez ética internalizada na ESB:

Desde que estou na área, dei sorte de abraçar bons profissionais que me acolheram, que me ensinaram mais do que eu já sabia. Então, se uma das outras meninas [TSBs] aqui pegaram um profissional que não teve o interesse de ensinar, elas não tiveram como crescer profissionalmente.

O cuidado da saúde bucal dos usuários não deve ser de responsabilidade ou um campo de competências de somente um profissional ou alguns profissionais, mas sim de vários. Nele, todos os saberes e fazeres dos profissionais que estejam envolvidos nesse processo de cuidado tornam-se recursos em potencial para defender a saúde (Cavalcanti Filho, 2009), para além de vaidades individuais. Mas, para isso, as coordenações de saúde bucal, no âmbito nacional, estadual e municipal precisam oferecer a orientação administrativa para a interpretação da lei n. 11.889/2008 (Zanetti, Oliveira e Mendonça, 2012), oferecendo um apoio gerencial para as ações (Conselho Regional de Odontologia de Minas Gerais, s.d.). Assim, o processo de interação pessoal, permeado pelas subjetividades e pelo processo de formação desses profissionais, pode ser capaz de modificar o resultado que se espera do trabalho em si, potencializando os benefícios aos usuários.

\section{Considerações finais}

As dificuldades que apareceram na análise do material empírico foram fiéis à metodologia aqui empregada. O desafio foi procurar evidenciar o que está 
oculto por excelência nas relações entre os profissionais da ESB, o que escapa, que está subjacente e que nos coloca uma pergunta: como superar esses conflitos? Não temos uma resposta, pois seria muito presunçoso de nossa parte, visto que outros métodos de investigação podem ser utilizados para tanger o social e o teórico abordado no presente estudo. A partir dessa reflexão, apresentam-se alguns pontos relevantes.

A complexidade que permeia o trabalho do TSB junto ao CD torna-se evidente, assim como o fato de não se limitar a questões técnicas, mas estender-se para um jogo de interesses, poder e resistências que envolvem os profissionais. As redes estabelecidas pelo conjunto de fatores alcançam o campo das relações, encontrando-se resquícios da dicotomia saber-fazer e saber-pensar, com valorização distinta entre os profissionais.

Sem o respaldo das instituições acadêmicas, de classe e de serviços, na busca por melhores condições de trabalho, os TSBs tornam-se submissos à autoridade dos CDs e da administração. Nesse contexto, há dificuldades de inserção do TSB no mercado de trabalho, possivelmente gerada por situações construídas ao longo da história da profissão, que obteve uma formação desvinculada da educação geral e sem uniformidade dentro da federação. Por isso, torna-se limitada a perspectiva de novos encontros.

Vislumbra-se a comunicação em saúde, com seus princípios básicos da ética e do respeito à opinião do outro, como mediadora da construção de novos encontros, caracterizados por uma relação horizontal entre os atores envolvidos e pelo conhecimento da realidade pessoal/profissional. A partir disso, por meio do diálogo, poderão ser sinalizados esforços para promover articulações de saberes que, somados, poderão favorecer a relação no trabalho e o próprio cuidado em saúde bucal. Assim, poderá contribuir para a conformação de um campo harmônico, com possibilidade de interação entre CDs e TSBs voltada para a colaboração no cuidado em saúde bucal.

Desta forma, a solidariedade, o respeito e a integração profissional na ESB devem ser exercidos diariamente para que o diálogo possa potencializar o entendimento e o planejamento de ações dos envolvidos, como a constituição de vínculo (Backes, Lunardi Filho e Lunardi, 2005). A partir disso, é possível que a sintonia no relacionamento entre CDs e TSBs, respeitando as suas singularidades, surja pela possibilidade de profanar o instituído com vistas a neutralizar os dispositivos de poder, que podem representar uma alternativa de superação dos desafios que se apresentam (Agamben, 2007). 


\section{Colaboradores}

Eunice Assad Galvêas, autora da dissertação de mestrado que deu origem a este artigo, concebeu e redigiu o texto. Adauto Emmerich foi responsável pela orientação da dissertação. Carolina Dutra Degli Esposti e Edson Theodoro dos Santos Neto colaboraram na pesquisa de campo e participaram da revisão do manuscrito. Os autores declaram que não há conflitos de interesse.

Resumen En este estudio se buscó comprender la relación entre técnicos en salud bucal y cirujanos dentistas en el trabajo y los factores que pueden favorecer o entorpecer esta relación. Para el análisis de la percepción de los técnicos en salud bucal sobre los posibles encuentros y desencuentros de la relación en el trabajo con los cirujanos dentistas, se realizó un grupo focal con ocho de estos trabajadores del Sistema Único de Salud de municipios de la Gran Vitória, Espírito Santo, Brasil. El análisis de contenido temático reveló tres categorías: Perfil y mercado de trabajo; Condiciones de trabajo e infraestructura; y Formación profesional, proceso de trabajo y relación interpersonal. La complejidad del trabajo se puso de manifiesto, dentro del campo de intereses, poder y resistencias, involucrando tanto a los técnicos como a los cirujanos dentistas en una matriz generadora de comportamientos. Existe también una fuerte influencia del sistema de formación de estos trabajadores, de la infraestructura y de las condiciones de trabajo y del perfil profesional en el proceso de trabajo del equipo en salud bucal. Se considera que muchos son los obstáculos para la relación entre técnicos en salud bucal y cirujanos dentistas en el trabajo, y se vislumbra en la comunicación la mediación, construyendo nuevos encuentros y representando alternativas para la profanación de lo instituido, con superación de los desafíos en las relaciones de poder.

Palabras clave personal técnico de salud; odontología en salud pública; relaciones interprofesionales; recursos humanos en odontología. 


\section{Notas}

1 Prefeitura Municipal de Vila Velha, Vila Velha, Espírito Santo, Brasil.

<euassad@yahoo.com.br>

Correspondência: Av. Champagnat, 689/601, Centro, CEP 29100-908, Vila Velha, Espírito Santo, Brasil.

2 Universidade Federal do Espírito Santo, Centro de Ciências da Saúde, Departamento de Medicina Social, Vitória, Espírito Santo, Brasil.

<adautoemmerich@terra.com.br>

3 Universidade Federal do Espírito Santo, Centro de Ciências da Saúde, Vitória, Espírito Santo, Brasil.

$<$ carolinaesposti@gmail.com>

4 Universidade Federal do Espírito Santo, Centro de Ciências da Saúde, Departamento de Medicina Social, Vitória, Espírito Santo, Brasil.

<edsontheodoro@uol.com.br>

5 Texto inédito, elaborado com base na dissertação de mestrado intitulada Cirurgião dentista e técnico em saúde bucal: encontros ou desencontros na relação no trabalho, de autoria de Eunice Assad Galvêas, apresentada em 2011 ao Programa de Pós-Graduação em Saúde Coletiva da Universidade Federal do Espírito Santo. A pesquisa não contou com financiamento.

\section{Referências}

AGAMBEN, Giorgio. Profanações. São Paulo: Boitempo Editorial, 2007.

BACKES, Dirce S.; LUNARDI FILHO, Wilson D.; LUNARDI, Valéria L. A construção de um processo interdisciplinar de humanização à luz de Freire. Texto \& Contexto Enfermagem, v. 14, n. 3, p. 427-434, set. 2005.

BARDIN, Laurence. Análise de conteúdo. São Paulo: Edições 70, 2009.

BOURDIEU, Pierre. Razões práticas: sobre a teoria da ação. Campinas, São Paulo: Papirus, 1996.

BOURDIEU, Pierre. Science of science and reflexivity. Cambridge: Polity, 2010.

BRASIL. Lei de Diretrizes e Bases da Educação Nacional (LDB). Lei n. 9.394, de 20 de dezembro de 1996. Diário Oficial da União, Brasília, 23 de dezembro de 1996. Disponível em: <www.planalto.gov.br/CCIVIL_03/leis/ L9394.htm>. Acesso em: 21 ago. 2015.

BRASIL. Ministério da Saúde. Portaria n. 1.444, de 28 de dezembro de 2000. Diário Oficial da República Federativa do Brasil, Brasília, 29 dez. 2000. Seção 1, p. 85.

BRASIL. Ministério da Saúde. Projeto SB Brasil 2003: condições de saúde bucal da população brasileira, 2002-2003. Resultados principais. Brasília, 2004.

BRASIL. Portaria interministerial MS/MEC n. 2.101, de 3 de novembro de 2005. Disponível em: <http://portal.saude.gov.br/portal/ arquivos/pdf/2101.pdf $>$. Acesso em: 15 jul. 2011. 
BRASIL. Portaria interministerial MS/MEC n. 1.802, de 26 de agosto de 2008. Disponível em: <http://bvsms.saude.gov.br/bvs/ saudelegis/gm/2008/pri1802_26_08_2008. html>. Acesso em: 15 jul. 2011.

CARVALHO, Cristiana L. Trabalho e profissionalização das categorias auxiliares em odontologia. Revista Ação Coletiva, Brasília, v. 2, n. 1, p. 25-33, jan./fev.1999.

CAVALCANTE FILHO, João B. Coletivos organizados para a produção do cuidado integral: um desafio para a regulamentação profissional. Revista APS, v. 12, n. 2, p. 214-220, abr.-jun. 2009.

CHAVES, Mario. Odontologia social. 2. ed. Rio de Janeiro: Editorial Labor do Brasil, 1977.

\section{CONSELHO REGIONAL DE ODONTOLOGIA} DE MINAS GERAIS (CRO-MG). Documento de consenso técnico. Orientação para o exercício profissional com base na lei n. 11.889/2008, que regulamenta o exercício das profissões de técnico em saúde bucal (TSB) e de Auxiliar em Saúde Bucal (ASB). CRO-MG: Belo Horizonte, s.d. Disponível em: <www.cromg. org.br>. Acesso em: 5 abr. 2014.

CRUZ NETO, Otávio et al. Grupos focais e pesquisa social: o debate orientado como técnica de investigação. Rio de Janeiro: Editora Fiocruz, 2001.

D'AMOUR, Danielle et al. The conceptual basis for interprofessional collaboration: core concepts and theoretical frameworks. Journal of Interprofessional Care, Abingdon, supl. 1, p. 116-131, maio 2005.

DEJOURS, Jacques C. A loucura do trabalho: estudo da psicopatologia do trabalho. São Paulo: Cortez, 1993.

EMMERICH, Adauto; CASTIEL, Luis D. A ciência odontológica, Sísifo e o 'efeito camaleão'. Interface: Comunicação, Saúde, Educação, Botucatu, v. 13, n. 29, p. 339-351, 2009.

EMMERICH, Adauto; FREIRE, Aprígio S. (org.). Flúor e saúde coletiva. 1. ed. Vitória: Edufes, 2003.
ESPOSTI, Carolina D. D. et al. O processo de trabalho do técnico em saúde bucal e suas relações com a equipe de saúde bucal na Região Metropolitana da Grande Vitória, Espírito Santo, Brasil. Saúde e Sociedade, São Paulo, v. 21, n. 2. p. 372-385, 2012.

FARIAS, Luís O.; VAITSMAN, Jeni. Interação e conflito entre categorias profissionais em organizações hospitalares públicas. Cadernos de Saúde Pública, Rio de Janeiro, v. 18, n. 5, p. 1.229-1.241, set.-out. 2002.

FERRETTI, Celso J. Formação profissional e reforma do Ensino técnico do Brasil: anos 90. Educação \& Sociedade, Campinas, n. 59, p. 225-269, ago.1997.

FLEURI, Reinaldo M. A questão da diferença na educação: para além da diversidade. In: REUNIÃO ANUAL DA ANPED, 25. Resumos. Caxambu: ANPed, GT 06 Educação Popular, p. 1-15, 2002.

FOUCAULT, Michel. A arqueologia do saber. 7. ed. Rio de Janeiro: Forense Universitária, 2007.

FRAZÃO, Paulo. A participação do pessoal auxiliar odontológico na promoção de saúde bucal. Revista de Odontologia da Universidade de São Paulo, São Paulo, v. 12, n. 4, p. 329-336, out.-dez. 1998.

FRAZÃO, Paulo; NARVAI, Paulo C. Sistemas de trabalho em odontologia: origens históricas e principais aplicações. In: PEREIRA, Antônio C. Tratado de saúde coletiva em odontologia. Nova Odessa: Napoleão, 2009. p. 201-216.

FRAZÃO, Paulo; NARVAI, Paulo C. Lei n. 11.889/2008: Avanço ou retrocesso nas competências do técnico em saúde bucal? Trabalho, Educação e Saúde, Rio de Janeiro, v. 9, n. 1, p. 109-123, mar.-jun. 2011.

FREIRE, Paulo. Pedagogia da esperança: um reencontro com a pedagogia do oprimido. 6. ed. Rio de Janeiro: Paz e Terra, 1999.

HALL, Pippa; WEAVER, Lynda. Interdiciplinary educacion and teamwork: a longand 
widing road. Medical Education, Oxford, v. 35 , p. $867-875,2001$.

LATOUR, Bruno. Jamais fomos modernos. Rio de Janeiro: Editora 34, 2008.

MALORY, Thomas. A morte de Arthur. Brasília: Thot, 1987.

MERHY, Emerson E. Saúde: a cartografia do trabalho vivo. São Paulo: Hucitec, 2002.

MINAYO, Maria C. S. O desafio do conhecimento: pesquisa qualitativa em saúde. São Paulo: Hucitec, 2008.

MORIN, Edgar. A cabeça bem feita: repensar a reforma, reformar o pensamento. Tradução de Eloá Jacobina. 8. ed. Rio de Janeiro: Bertrand Brasil, 2003.

NARVAI, Paulo C. et al. Contra o técnico em higiene dental. Saúde em Debate, Rio de Janeiro, n. 28, p. 59-65, mar. 1989.

OLIVEIRA, Adriano et al. A comunicação no contexto do acolhimento em uma unidade de saúde da família de São Carlos, SP. Interface: Comunicação, Saúde e Educação, Botucatu, v. 12, n. 27, dez. 2006.

PARANHOS, Luiz R. et al. Análise da relação entre o cirurgião-dentista e o pessoal auxiliar. Revista Odonto Ciência, Porto Alegre, v. 23, n. 4, p. 365-370, 2008.

PEDROSA, José I. S.; TELES, João B. M. Consenso e diferenças em equipes do programa da saúde da família. Revista de Saúde Pública, São Paulo, v. 35, n. 3, p. 303-311, 2001.

PEREIRA, Antônio C. Operatória Dentária. In: BOTAZZO, Carlos; OLIVEIRA, Maria A. Atenção básica no Sistema Único de Saúde: abordagem interdisciplinar para os serviços de saúde bucal. São Paulo: Páginas e Letras, 2008. p. 173-180.

PEZZATO, Luciane M. A Formação para o pessoal auxiliar em odontologia no Brasil: contribuição ao tema. Revista Ação Coletiva, Brasília, v. 2, n. 1, p.35-40, jan.-fev. 1999.
PUCCA JR., Gilberto A. A política nacional de saúde bucal como demanda social. Ciência \& Saúde Coletiva, Rio de Janeiro, v. 11, n. 1, p. 243-246, 2006.

RICHARDSON, Roberto J. Pesquisa social: modelos e técnicas. 3. ed. São Paulo: Atlas, 1999.

SAN MARTÍN-RODRÍGUEZ, Leticia et al. The determinants of successful collaboration: a review of theoretical and empirical studies. Journal of Interprofessional Care, Abingdon, v. 19, supl. 1, p. 132-47, maio 2005.

SERRA, Mônica C.; GARCIA, Patrícia P. N. S. Delegação de funções: utilização de pessoal auxiliar na clínica odontológica. Revista $A B O$ Nacional, São Paulo, v. 10, n. 2, p. 98-104, abr.-maio 2002.

SCHRAIBER, Lilia B. et al. Planejamento, gestão e avaliação em saúde: identificando problemas. Ciência \& Saúde Coletiva, Rio de Janeiro, v. 2, n. 4, p. 221-242, 1999.

TEIXEIRA, Ricardo R. Humanização e Atenção Primária à Saúde. Ciência \& Saúde Coletiva, Rio de Janeiro, v. 10, n. 3, p. 585-597, 2005.

ZANETTI, Carlo H. G. Observatório de recursos humanos em saúde. Brasília, DF: Abrasco, 2009.

ZANETTI, Carlo H. G.; OLIVEIRA, José A. A.; MENDONÇA, Maria H. M. Divisão do trabalho odontológico em perspectiva: desafio de interpretar as competências dos técnicos. Trabalho, Educação e Saúde, Rio de Janeiro, v. 10 n. 2, p.195-222, jul.-out.2012.

Recebido em 14/03/2013

Aprovado em 11/02/2015 